\title{
Usefulness of Comprehensive High - Resolution Ultrasound Imaging in Dermatologic Field: Epidermal Cyst
}

\author{
Kazumi Fujioka* \\ Division of Laboratory Medicine, Department of Pathology and Microbiology, Nihon University, School of Medicine, Japan
}

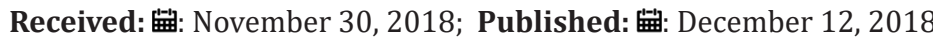

*Corresponding author: Kazumi Fujioka, Division of Laboratory Medicine, Department of Pathology and Microbiology, Nihon University School of Medicine, add “30-1, Oyacughi-kamicho, Itabashi-ku, Tokyo”, Japan

\begin{abstract}
Dermatologic ultrasound (US) has been growing rapidly in line with the development of more potent machines and high-frequency probes. The minimum frequency recommended for performing dermatologic examinations was $15 \mathrm{MHz}$. Epidermal Cyst is a common slow-growing dermal or subcutaneous epithelial cyst, which contains keratin and is lined by the epidermis. Epidermal cyst is considered as level 1 content of the training program in dermatologic ultrasound by the international working group, called DERMUS (Dermatologic Ultrasound). I review the characteristic findings of epidermal cyst on high-resolution US including gray-scale, color Doppler and Real-Time Tissue Elastography (RTE). Epidermal cyst has been reported as a pseudotestis pattern and nonpseudotestis one on gray scale US. In relation to color Doppler US, unruptured type of epidermal cyst represented no substantial blood flow signals and ruptured type shows pericystic and peripheral vascularity. It is reported that superficial epidermoid tumor shows a softer nature than dose malignant tumor on RTE. It is also reported that RTE is able to detect differences in tissue elasticity between ruptured and unruptured epidermal cysts. The comprehensive procedure using high-resolution ultrasound is useful for the accurate diagnosis of epidermal cyst.
\end{abstract}

Keywords: Dermatologic Ultrasound; High-Resolution Ultrasonography; Real-Time Tissue Elastography; Color Doppler Ultrasonography; Comprehensive Procedure, Epidermal Cyst

Abbreviations: US: Ultrasound; RTE: Real Time Tissue Elastography; DERMUS: Dermatologic Ultrasound; SE: Strain Elastography

\section{Introduction}

Dermatologic ultrasound imaging has been rapidly growing in recently years because of the development of high-resolution multifrequency transducers and multichannel color Doppler machines [1]. The international working group, called DERMUS (Dermatologic Ultrasound) was formed and provided the guidelines for performing dermatologic ultrasound examinations [1] and proposed for an assessment training program [2]. The minimum frequency recommended for performing dermatologic examinations was $15 \mathrm{MHz}$ [2]. Epidermal Cyst is a common slowgrowing dermal or subcutaneous epithelial cyst, which contains keratin and is lined by the epidermis [3]. It has been reported that epidermal cyst shows 2 types as pseudotestis and nonpseudotestis types on gray-scale US [4]. Epidermal cysts classically show a round-to-oval shape with posterior echo enhancement and lateral shadow on gray-scale US [5]. As the unruptured type of epidermal cyst represented no substantial blood flow signals, the ruptured type shows pericystic and peripheral vascularity [6] and prominent vascularity in the periphery [7] on color Doppler US. Real-time sonoelastography is an ultrasound-based technique using the property that the tissue strain due to compression is lower in hard tissues [8]. RTE is widely used for diagnosis of breast [9] and thyroid lesions [10] on tissue elasticity. There have been reported that the TRE is still uncommon in the dermatologic field. Patel, et al. [11] reported that most epidermoid tumors show a predominant blue color, which represents their hard nature. Park HJ, et al. [11,12] suggested that superficial epidermoid tumor exhibits a softer nature than dose malignant tumor but does not have a different strain elastography (SE) pattern from other benign tumors [12]. It has been reported that utility of sonoelastography in differentiating ruptured from unruptured epidermal cyst [5], suggesting the differences in tissue elasticity.

\section{Dermatologic Ultrasound}

Dermatologic ultrasound imaging has been rapidly growing in recently years because of the development of high-resolution 
multifrequency transducers and multichannel color Doppler machines [1]. An international working group, called DERMUS proposed that the contents for level 1 include basic ultrasound knowledge, normal dermatologic ultrasound anatomy, and common pathologic condition [2]. The minimum frequency recommended for performing dermatologic examinations was $15 \mathrm{MHz}$. We usually perform US examinations for dermatologic diseases with a high-resolution, broad-band $(5 \mathrm{MHz}-18 \mathrm{MHz})$ linear transducer (Nobulus Hitachi, Ltd. Tokyo, Japan). Until now, we have reported some studies in relation to the skin and subcutaneous disease [1317]. Epidermal cyst is considered as level 1 content of the training program in dermatologic ultrasound by the international working group, called DERMUS [2].

\section{Epidermal Cyst}

Epidermal Cyst is a common slow-growing dermal or subcutaneous epithelial cyst, which contains keratin and is lined by the epidermis [3]. As the rate of malignant transformation into squamous cell carcinoma has been reported to range from $0.01 \%$ to $2.00 \%[4,12,18]$, accurate diagnosis of epidermal cyst is very important for the establishment of the treatment plan. It is also difficult to distinguish an epidermal cyst from other benign skin tumors, such as pilomatricoma, lipoma, steatocytoma, dermatofibroma and intradermal nevus. The cosmetic outcome is less favorable in cases of inflamed or ruptured cysts because these cysts have indistinct margins, more friable cyst walls, and difficulty in complete removal owing to inflammation and fibrosis of the surrounding tissue. Therefore, preoperative diagnosis is important, and different treatment options should be planned for ruptured and unruptured cysts [5].

\section{Gray Scale Ultrasonographic Features}

It has been reported epidermal cyst shows 2 types as pseudotesis and nonpseudotestis [4] and the report of the classification of 5 patterns [3]. Pseudotestis type is mostly accompanied with filiform anechoic areas consistent with packed keratin lamellae, echogenic reflectors consistent with cholesterol, sebaceous foci, or calcifications. Nonpseudotestis type is mostly depicted as concentric ring sign which is consistent with alternating layers of laminated keratin and squamous cells [4]. Figure 1a showed an ovoid nodule with a laminated, concentric ring pattern with hypoechoic rim, called nonpsendotestis type of epidermal cyst pathologically confirmed. Other features are dermal attachment, focal dermal protrusion [4].

\section{Color Doppler Ultrasonographic Features}

Unruptured type shows usually no substantial blood flow. On the other hand, pericystic changes are demonstrated on grayscale US and color Doppler US shows pericystic and/or peripheral vascularity in ruptured type. A few peripheral blood flow signals were depicted on power Doppler US (Figure 1b). It has been reported that peripheral low echoic rim, consistent with the capsule was detected in $67 \%$ on gray-scale US [19]. It has been suggested that thin and smooth rim enhancement is shown in unruptured type, thick and irregular rim enhancement is represented in ruptured type on enhanced MRI [20]. The rim enhancement might be due to fibrosis and foreign body reaction around the cyst wall remnants and keratinous material [21].
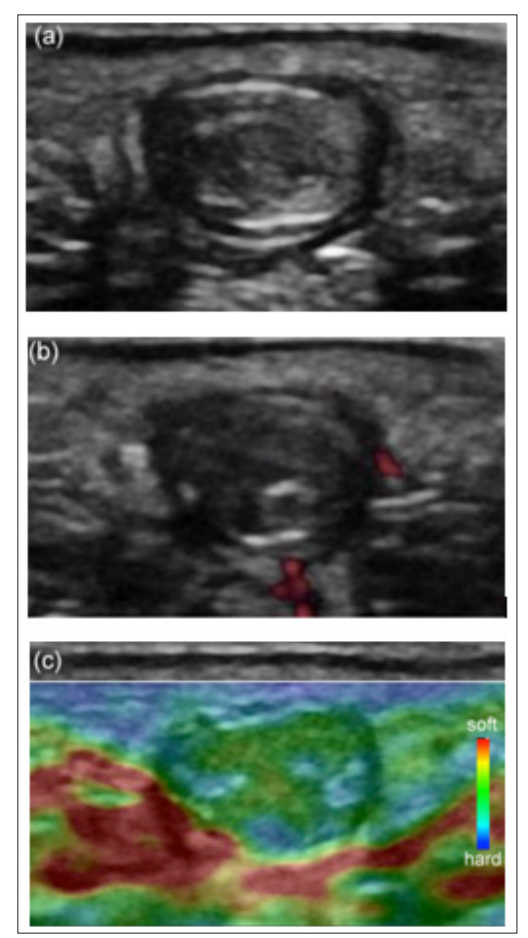

Figure 1: Nonpseudotestis type of epidermal cyst pathologically confirmed in the plantar in a 16-year-old female.

(a) On gray-scale US showed an ovoid nodule with a laminated, concentric ring pattern with hypoechoic rim.

(b) A few peripheral blood flow signals were depicted on power Doppler US.

(c) Real-time tissue elastography showed more green than blue.

\section{Real-Time Tissue Elastography Features}

Recently, it has been reported that the usefulness of elastography is described in dermatologic field [22]. RTE is widely used for diagnosis of breast. Rago T, et al. $[9,10]$ suggested that low elasticity of thyroid nodules on ultrasound elastography is correlated with malignancy, degree of fibrosis. Park HJ et al. described that the strain elastography grades was from one to four as follows; Score 1 shows very soft nature, high elasticity. Score 2 represents moderate soft nature, moderate high elasticity. Score 3 is consistent with moderately hard nature, moderately low elasticity. Score 4 shows very hard nature, low elasticity. On RTE, they concluded that superficial epidermoid tumor shows a softer nature than dose malignant tumor; however, it does not have a different SE pattern from other benign tumors. (Figure 1c) shows relatively soft nature on RTE as previously reported [12]. The lipoma is hyperechoic compared with the subjacent muscle but isoechoic as compared with the adjacent subcutaneous adipose tissue. Gently curved echogenic lines were showed within the lipoma [23]. Lipoma represented green to orange color, showing 
grade 1 as previously reported [12]. This case was comprehensively diagnosed as a lipoma using high-resolution ultrasound imaging Lipoma represent green color with a lot of orange color, suggesting soft nature on RTE (Figure 2a). Gently curved echogenic lines were noted on gray-scale US (Figure 2b). Ruptured type is softer nature than unruptured type on RTE. Park J et al. reported that RTE is able to detect differences in tissue elasticity between ruptured and unruptured epidermal cysts. Park et al. evaluated that US features of superficial epidermoid tumor with a focus on SE features that will help in the differential diagnosis of epidermoid tumor from other benign and malignant soft-tissue tumors. They concluded that superficial epidermoid tumor shows a softer nature than dose malignant tumor; however, it does not have a different SE pattern from other benign tumors [12].

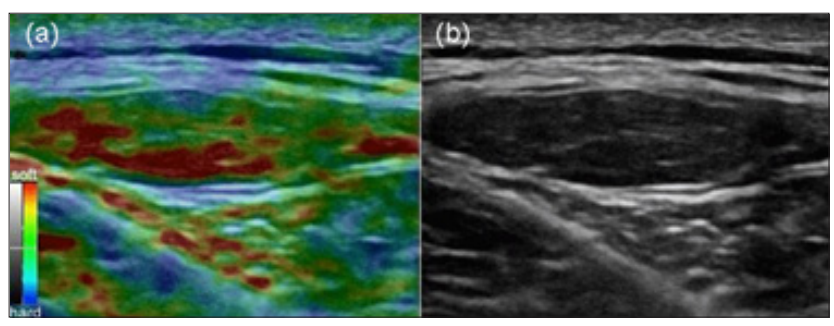

Figure 2:

(a) This case was comprehensively diagnosed as a lipoma using high-resolution ultrasound imaging. Lipoma showed green color with a lot of orange color, suggesting softer nature than epidermal cyst on RTE.

(b) Gently curved echogenic lines were obtained in the mass on gray-scale US.

\section{Conclusion}

Pseudotestis and nonpseudotestis types on gray scale US and pericystic and peripheral vascularity in ruptured type on color Doppler US were represented. A softer nature than malignant tumor and the differences in tissue elasticity between ruptured and unruptured epidermal cysts on RTE were shown. These comprehensive tools using high-resolution ultrasound including gray-scale US, color Doppler US and RTE are useful for the accurate diagnosis of epidermal cyst.

\section{References}

1. Wortsman X, Alfageme F, Roustan G, Arias Santiago S, Martorell A, et al. (2016) Guidelines for performing dermatologic ultrasound examinations by the DERMUS group. J Ultrasound Med 35(3): 577-580.

2. Wortsman X, Alfageme F, Roustan G, Arias Santiago S, Martorell A, et al. (2016) Proposal for an assessment training program in dermatologic ultrasound by the DERMUS group. J Ultrasound Med 35(11): 2305-2309.

3. Lee HS, Joo KB, Song HT, Kim YS, Park DW, et al. (2001) Relationship between sonographic and pathologic findings in epidermal inclusion cysts. J Clin Ultrasound 29(7): 374-383.

4. Huang CC, Ko SF, Huang HY, Ng SH, Lee TY, et al. (2011) Epidermal cysts in the superficial soft tissue: sonographic features with an emphasis on the pseudotestis pattern. J Ultrasound Med 30(1): 11-17.

5. Park J, Chae IS, Kwon DR (2015) Utility of sonoelastography in differentiating ruptured from unruptured epidermal cysts and implications for patient care. J Ultrasound Med 34(7): 1175-1181.
6. Jin W, Ryu KN, Kim GY, Kim HC, Lee JH, et al. (2008) Sonographic findings of raptured epidermal inclusion cysts in superficial soft tissue: emphasis on shapes, pericystic changes, and pericystic vascularity. J Ultrasound Med 27(2): 171-176.

7. Wortsman X (2017) Sonography of dermatologic emergencies. J Ultrasound Med 36(9): 1905-1914.

8. Ito A, Ueno E, Tohno E, Kamma H, takahashi H, et al. (2006) Breast disease: clinical applications of US elastography for diagnosis. Radiology 239(2): 341-350.

9. Nakashima K, Shiina T, Sakurai M, Enokido K, Endo T, et al. (2013) JSUM ultrasound elastography practice guidelines: breast. J Med ultrason 40(4): 359-391.

10. Rago T, Scutari M, Loiacono V, Santin F, Tonacchera M, et al. (2017) Low elasticity of thyroid nodules on ultrasound elastography is correlated with malignancy, degree of fibrosis, and high expression of galectin-3 and fibronectin-1. Thyroid 27(1): 103-110.

11. Patel K, Sellars ME, Clarke JL, Sidhu PS (2012) Features of testicular epidermoid cysts on contrast-enhanced sonography and real-time tissue elastography. J Ultrasound Med 31(1): 115-122.

12. Park HJ, Lee SY, Lee SM, Kim WT, Lee S, et al. (2015) Strain elastography features of epidermoid tumours in superficial soft tissue: differences from other benign soft-tissue tumours and malignant tumours. Br J Radiol 88(1050): 20140797.

13. Fujioka K, Fujioka A, Eto H, Suzuki K, Sanuki E, et al. (2006) Nodular fascitis in the thigh followed up using ultrasonography. J Med Ultrason 33: 49-53.

14. Fujioka K, Fujioka A, Oishi M, Eto H, Tajima S, et al. (2017) Ultrasonography findings of intradermal nodular fasciitis; a rare case report and review of the literature. Clin Exp Dermatol 42(3): 335-336.

15. Fujioka K, Fujioka A, Tajima S, Oishi M, Hayashi K, et al. (2018) Characteristic power Doppler sonographic imaging of nodular fasciitis from a dermatological perspective: another case and review of three cases. J Clin Case Rep 8(9): DOI: 10.4172/2165-7920.10001165.

16. Fujioka K, Fujioka A, Oishi M, Hayashi K, Nakayama T (2018) Highresolution ultrasound imaging for angioleiomyoma: a painful and vascularized superficial tumor. Biomed J Sci \& Tec Res. 9(5), DOI: 10.26717/BJSTR.2018.09.001857.

17. Fujioka K (2018) Presentations of clinical, ultrasonographic and pathological features of nodular fasciitis from an established cytogenetic viewpoints: review of the case series. J Carcinog Mutagen 9(4). DOI: 10.4192/2159-2518.1000326.

18. Ziadi S, Trimeche MHammedi F, Sriha B, Jomaa W, et al. (2010) Squamous cell carcinoma arising from an epidermal inclusion cyst: a case report. $\mathrm{N}$ Am J Med Sci 4(3): 46-47.

19. Kim HK, Kim SM, Lee SH, Racadio JM, Shin MJ (2011) Subcutaneous epidermal inclusion cysts: ultrasound (US) and MR imaging findings. Skeletal Radiol 40(11): 1415-1419.

20. Hong SH, Chung HW, Choi JY, Koh YH, Choi JA, et al. (2006) MRI findings of subcutaneous epidermal cysts: emphasis on the presence of rupture. AJR 186(4): 961-966.

21. Fisher AR, Mason PH, Wagenhais KS (1998) Ruptured plantar epidermal inclusion cyst. AJR 171(6): 1709-1710.

22. Hata H, Natsuga K, Aoyagi S, Homma E, Shimizu H (2014) Ultrasound B-mode and elastographic findings of angiomatoid fibrous histochytoma. Clin Exp Dermatol 39(4): 538-539.

23. Wagner JM, Lee KS, Rosas H, Kliewer MA (2013) Accuracy of sonographic diagnosis of superficial masses. J Ultrasound Med 32(8): 1443-1450. 


\section{ISSN: 2574-1241}

DOI: $10.26717 / B J S T R .2018 .12 .002184$

Kazumi Fujioka. Biomed J Sci \& Tech Res

(c) (i) This work is licensed under Creative

Submission Link: https://biomedres.us/submit-manuscript.php

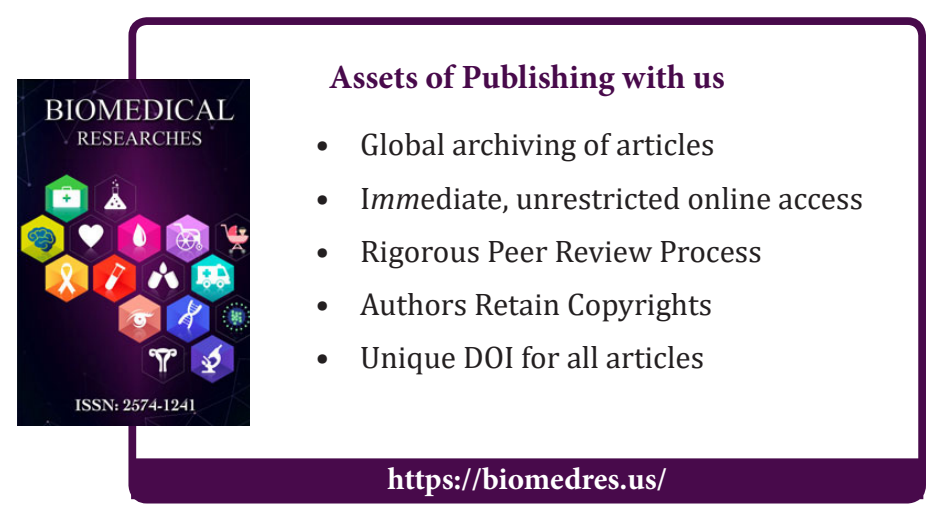

